\author{
Abstracta Iranica \\ Abstracta Iranica Revue bibliographique pour le domaine irano-aryen \\ Volume 32-33 | 2013 \\ Comptes rendus des publications de 2009-2010
}

\title{
F. Briquel Chatonnet, M. Debié (dirs). Sur les pas des Araméens. Mélanges offerts à Alain Desreumaux
}

\section{Denise Aigle}

\section{OpenEdition}

1 Journals

\section{Édition électronique}

URL : http://journals.openedition.org/abstractairanica/39929

DOI : 10.4000/abstractairanica.39929

ISSN : 1961-960X

Éditeur :

CNRS (UMR 7528 Mondes iraniens et indiens), Éditions de l'IFRI

\section{Édition imprimée}

Date de publication : 1 décembre 2013

ISSN : 0240-8910

Référence électronique

Denise Aigle, «F. Briquel Chatonnet, M. Debié (dirs). Sur les pas des Araméens. Mélanges offerts à Alain Desreumaux », Abstracta Iranica [En ligne], Volume 32-33 | 2013, document 4, mis en ligne le 01 juillet 2016, consulté le 26 septembre 2020. URL : http://journals.openedition.org/abstractairanica/39929 ; DOI : https://doi.org/10.4000/abstractairanica.39929

Ce document a été généré automatiquement le 26 septembre 2020.

Tous droits réservés 


\title{
F. Briquel Chatonnet, M. Debié (dirs). Sur les pas des Araméens. Mélanges offerts à Alain Desreumaux
}

\author{
Denise Aigle
}

\section{RÉFÉRENCE}

F. Briquel Chatonnet, M. Debié (dirs). Sur les pas des Araméens. Mélanges offerts à Alain Desreumaux. Paris, Geuthner, 2010, 448 p. (Cahiers d'études syriaques 1)

1 Cet ouvrage d'hommages est constitué de trente et une contributions sur la culture syriaque à laquelle Alain Desreumaux a consacré sa vie de chercheur. Il a abordé et fait considérablement progresser les études syriaques dans trois domaines principaux : les manuscrits, la littérature apocryphe et les inscriptions, allant toujours à la découverte de traditions textuelles originales. Une importante partie de ce livre concerne la littérature apocryphe («Constellations apocryphes », p. 25-155). Dans sa contribution, Muriel Debié (p. 63) considère, à juste titre, que les textes apocryphes ont joué le rôle de «romans avant la lettre", tout en ayant une dimension historique marquée. Un texte «source » peut en effet donner suite à diverses transmissions nouvelles ayant chacune sa propre histoire. Un autre ensemble de contributions s'intéresse aux manuscrits ("Ce que disent les manuscrits », p. 159-256). On trouvera une intéressante étude de S. Brock sur les signatures en chiffres arithmétiques dans les manuscrits syriaques de la British Library. L'A. suggère (p. 166) que cette pratique a sans doute été influencée par le système alphabétique grec. Les articles regroupés dans la troisième partie («Les pierres et les objets », p. 259-323) témoignent de l'intérêt et de la diversité des inscriptions et des sites où elles ont été retrouvées. Enfin, un certain nombre d'études sont consacrées aux pratiques religieuses et aux contacts entre chrétiens et manichéens. Il est impossible de rendre compte de la richesse de ce gros volume 
d'hommages (448 p.), mais il témoigne de la vitalité des études syriaques dont Alain Desreumaux a été l'un des fers de lance.

\section{AUTEURS}

\section{DENISE AIGLE}

EPHE, Paris 